\title{
A case-control study of childhood pedestrian injuries in Perth, Western Australia
}

\author{
Mark Stevenson, Konrad Jamrozik, Paul Burton
}

\begin{abstract}
Study objectives - To identify the determinants of childhood pedestrian injuries, taking the child's exposure to the road environment into account.

Design - This was a case-control study.

Setting and participants - The study was conducted in Perth, Western Australia between 1991 and 1993. Altogether 100 injured and 400 uninjured child pedestrians aged 1 to 14 years were studied. Aspects of the child's social and physical environments, measures of his or her behaviour, cognitive skills, and "habitual" exposure to the road environment, as well as his or her knowledge of road safety, were recorded.
\end{abstract}

Main results - The likelihood of injury increased by $12 \%$ with each 10000 vehicles per day increase in the volume of traffic (odds ratio (OR) $1 \cdot 12$, 95\% confidence interval $(C I)=1 \cdot 05,1 \cdot 19)$ on roads most frequently crossed. In addition, the presence of visual obstacles on the verge of the child's street of residence increased the likelihood of injury by more than 2.6 times (OR $2 \cdot 68,95 \% \mathrm{CI}=1 \cdot 42,5 \cdot 02)$. In contrast, the absence of footpaths was associated with a $52 \%$ reduction in the likelihood of injury compared with the presence of footpaths on the child's street of residence (OR $0.48,95 \% \mathrm{CI}=0.27,0.87$ ).

Conclusion - The amount of exposure to the road environment and the nature of the road environment to which the child pedestrian was exposed partly influenced the likelihood of injury in children from low socioeconomic areas, male children, and children aged 13 to 14 years. Until now, the excess incidence of childhood pedestrian injuries in these subgroups of the population had not been explained because the child's exposure per se had not been examined.

( $($ Epidemiol Community Health 1996;50:280-287)

TVW Telethon Institute for Child Health Research, PO Box 855, West Perth, Western Australia 6872 P Burton

Correspondence to: Dr M Stevenson, National Center for Injury Prevention and Control, Centers for Disease Control and Prevention, 4770 Buford Highway, NE (K63), Atlanta, Georgia 3-0341-3724, USA.

Accepted for publication December 1995 sequently, motor vehicle related injuries to children are a significant health problem in western society. ${ }^{1}$
Each year in Australia approximately 110 children die and a further 1800 are admitted to hospital as a result of collisions between pedestrians and motor vehicles. ${ }^{2}$ In Western Australia alone (total population 1.7 million), childhood pedestrian injuries account for 1300 bed-days per year, with most injuries admitted being fractures $(40 \%)$ and intracranial and other internal injuries $(30 \%){ }^{3}$ Andreassen $^{45}$ estimated the direct costs of a pedestrian injury in urban or rural environments in Australia to be $A \$ 89000$ and $A \$ 104000$, respectively. These are estimates for pedestrian morbidity alone. If one then considers the potential years of life lost for fatal pedestrian injuries, the cost is even greater.

The child pedestrian fatality rate for Western Australian children aged 1 to 14 years of $3 \cdot 2 /$ 100000 per year $^{6}$ is higher than that for children aged 1 to 14 years in Australia as a whole ( $3 \cdot 1 / 100000$ per year), and is also higher than the rates for the United Kingdom ${ }^{7}(2 \cdot 4 / 100000$ per year) and the United States of America $(2 \cdot 4 / 100000 \text { per year })^{8}$ for children of the same age range. The lack of any significant reduction in the mortality rates from pedestrian injury in Western Australia over the past decade ${ }^{6}$ suggests that child pedestrian injury will continue to represent a major child health problem if efforts are not directed at prevention. However, at present there are few well established prevention strategies.

Children aged 5 to 9 years and males are over represented in pedestrian injuries. There is some disagreement in the published reports about explanations for these characteristics. Some researchers suggest that boys aged 5 to 9 years have an increased exposure to the road environment $^{910}$ while others ${ }^{112}$ attribute the over representation to the child's behaviour when crossing the road. However, few studies have formally examined whether the over representation of boys aged 5 to 9 years is actually a result of the amount of exposure to the road environment. The analytical studies published to date ${ }^{13-16}$ have either not measured the child's exposure to the road environment or, alternatively, they have a number of methodological constraints. For example, Pless, Verreault and Tenina ${ }^{13}$ and Backett and Johnson $^{14}$ matched control subjects to injured pedestrians by sex. Consequently then, sex cannot be assessed in terms of its relationship to injury in either of these studies.

The usual descriptive statistics for child pedestrian injuries are crude measures that rest on an untested assumption that children of different ages, sexes, and areas of residence, 
for example, spend equal amounts of time in equally dangerous traffic conditions. Consequently, research is needed in order to identify, firstly, those features of the descriptive epidemiology that are artefacts arising from differences in children's exposure in the road environment and, secondly, those features within the individual and the physical environment that have a significant influence on the likelihood of a collision. Without such research, preventive strategies will be based inappropriately on the somewhat unsophisticated descriptive studies currently available.

The race of the child, in terms of white versus non-white, is also associated with differences in rates of pedestrian injury. ${ }^{17-20}$ So, too, is a pattern of socioeconomic disadvantage associated with higher rates of pedestrian injury. ${ }^{172122}$ However, the family's or child's socioeconomic status has seldom been comprehensively measured by researchers. Frequently only one variable (such as the father's occupation) has been used as a measure of socioeconomic status. ${ }^{23}$ Further research incorporating a comprehensive assessment of the child's or family's socioeconomic environment is needed to determine to what extent socioeconomic factors are associated with childhood pedestrian injury.

A scarcity of controlled studies examining the relationship between developmental abilities and child pedestrian injury is evident in the published reports. If one considers that the learning processes of children are likely to remain the same, while the number of motor vehicles in the community increases, it is likely that the pedestrian task will become further complicated in the future. Consequently, in order to initiate appropriate prevention programmes, it is necessary to determine whether, in fact, the distribution of pedestrian injuries is related to the cognitive abilities and developmental stage of children.

Associations between childhood pedestrian injuries and each of the volume and speed of traffic, and the absence of play areas have also been reported. ${ }^{2425}$ However, the research to date has not applied sufficiently reliable and valid methods of measurement or included sufficient numbers of subjects to determine the contribution made by relevant traffic factors to the risk of pedestrian injury. Furthermore, few studies have compared the prevalence of specific physical environmental features such as the presence of traffic control devices in the neighbourhoods of injured children, with the prevalence of such features in the neighbourhoods of uninjured children. More research is required to increase our understanding of the influence of these factors and to identify aspects of the traffic environment that can be modified to reduce pedestrian injuries among children.

The present case-control study was conducted in the metropolitan area of Perth (total population 1.2 million), Western Australia between December 1991 and December 1993, and was carefully designed to address the methodological flaws found in previous studies.

\section{Methods}

Case subjects were children aged 1 to 14 years who had sustained an injury in a collision with a motor vehicle while walking, running, or, in the case of infants, crawling on a roadway, road verge, or footpath in the Perth metropolitan area. Cases were identified prospectively from December 1991 to December 1993 through a number of monitoring systems established at the only paediatric hospital in Perth (Princess Margaret Hospital for Children), the Health Department of Western Australia, and the Western Australian Police Department. When a case subject was identified, the parent or guardian and the injured child were invited by letter to participate. Children injured while riding bicycles or skateboards or injured by a non-motorised vehicle such as a bicycle were excluded from the study.

Of the 214 children injured as pedestrians, $15 \%(n=32)$ could not be contacted. Of the remaining 182 children that could be contacted, $30 \%(n=65)$ proved to be ineligible. One hundred of the remaining 117 were recruited, a corrected response rate of $85 \%$.

Four hundred non-injured controls were selected from either a list of all public and private primary and secondary schools in the Perth metropolitan area or the Midwives Notification System. Schools were selected with a sampling probability that was proportional to the number of children on the school roll, and which reflected the ratio of public to private schools of $2 \cdot 4: 1$. Controls were frequency matched to cases, with age (three strata) and sex as frequency matching variables. Preschool age (1 to 4 years) control subjects were randomly selected from the Midwives Notification System (one of only two population based registers of preschool age) and frequency matched to cases of preschool age. Selected controls of preschool age were traced via immunisation records, telephone directories, and electoral enrolments. Letters were then sent inviting the parents or guardians and their child to participate in the study. Of the 499 households ( $77 \%$ ) with which contact was made, 16 proved ineligible to participate. The response rate for the remaining 483 households was $83 \%$ ( $n=$ 400).

For both cases and controls, face to face structured interviews were undertaken with both parents or guardians and the child. The interview covered six well defined sets of characteristics of the child. Firstly, a comprehensive social index, as described by Osborn and Morris, ${ }^{26}$ was used to rank families along a continuum of social and economic inequality. Secondly, measures of the child's exposure to the road environment, such as the number of walking trips usually undertaken in a period of seven days, the number of roads crossed, and the volume of traffic on the roads crossed (volume was obtained from the local government engineers) were recorded. The volume of traffic was recorded for the road(s) most frequently crossed during the day, or, if the frequency of crossing was the same for each road, the road with the greatest volume of traffic was recorded. The child's habitual exposure to the road en- 
vironment was recorded rather than the exposure of the child to the road environment in the week preceding the interview as the latter might have been affected by the occurrence of the injury. Furthermore, recording the case or control subject's habitual exposure to the road environment overcame the problem of recording a particular week that happened to be atypical and thus either overestimating or underestimating the child's exposure to the road environment.

The third aspect of the interview measured the behaviour of cases and controls using a valid and reliable instrument developed by Jellinek and Murphy, ${ }^{27}$ the pediatric symptom checklist (PSC). The PSC identifies children who have sufficient behavioural problems to warrant referral to a physician for further evaluation and treatment. The fourth component of the interview schedule measured one aspect of the child's development namely, figure-ground discrimination, using a subtest of the Illinois test of psycholinguistic abilities (ITPA) ${ }^{28}$ This test has direct application to the road environment. In it children need to discern moving vehicles which can often be partly obscured from the surrounding environment.

The final set of questions elicited both the child's and parent's or guardian's knowledge of road safety. The children and their parents or guardians were asked to list the necessary procedures in order to cross the road safely. Other questions such as, "At what age would a child be capable of crossing a road safely?" were also asked, but only to the parents or guardians.

Information was also sought from the cases on the date and time of the injury, the exact location of the injury, the speed limit and road hierarchy at the site of injury, and the environmental conditions - for example, the weather prevailing at the time. Road hierarchy was an ordinal variable based on the volume of traffic on the road namely: cul de sac, residential road, sub arterial road, and arterial road. The case subject's medical record was also reviewed in order to classify the severity of injury using the abbreviated injury scale (AIS). ${ }^{29}$ Direct observation of the physical environment at each case and control subject's street of residence was also undertaken. Onstreet parking and other features of the roadway such as the road type, posted speed limit, the number of lanes in the street, the presence of footpaths, whether the street had specific traffic control devices, and whether there were visual obstacles in the street which could obscure the child's or driver's vision were recorded.

\section{STATISTICAL ANALYSIS}

Univariate statistics were computed from the final data set using the Statistical Analysis System (SAS) software. ${ }^{30}$ Proportions were presented as percentages of the respective denominator (n). Variations in proportions between cases and controls were initially assessed using the standard $\chi^{2}$ test for association, with continuity correction where appropriate. Odds ratios (ORs) and $95 \%$ confidence intervals (95\% CI) were derived using the standard methods for case-control studies as outlined by Breslow and Day. ${ }^{31}$ The independent contributions to the overall risk of pedestrian injury in children of variables shown to be significant in the univariate analyses were assessed using unconditional multiple logistic regression on EGRET software. ${ }^{32}$ Two models were constructed.

The first model used data for respondents aged 4 to 14 years $(n=457$, cases, $n=97$, controls $n=360$ ). The reason for limiting the age group was the restrictions placed on the use of the PSC which has been validated only for children aged 4 to 14 years. Consequently, the first model included the score on the PSC and 41 other variables. The second model used the variables found to explain the risk of childhood pedestrian injury in the first model, but was restricted to the age group 4 to 10 years $(n=289)$ in order to assess the only other variable in the data set which had an age restriction, namely the figure-ground discrimination test (ITPA). ${ }^{28}$

One of the objectives in this study was to determine the extent to which differences in the amount of exposure can explain the age and sex pattern of child pedestrians who are injured most frequently. However, because coarse frequency matching by age and sex was undertaken in this study, it meant that the effects of age and sex could not be interpreted directly. The effects of frequency matching were, therefore, overcome by applying an "offset" which contrasted the difference between the probability of a child in the general population being in a specific age and sex category compared with the equivalent probability in a control subject (see Appendix).

\section{ETHICAL APPROVAL}

The study was approved by the research and ethics committees of all organisations involved in the project. In accordance with the guidelines of the National Health and Medical Research Council, ${ }^{33}$ parents or guardians consented to their own and to their child's participation in this research.

\section{Results}

Within the case group $65 \%(n=65)$ were male whilst in the control group, $57 \%(n=230)$ were male. These proportions are not significantly different $\left(\chi^{2}=1 \cdot 79, \mathrm{df}=1, \mathrm{p}=0 \cdot 19\right)$. There was a significant difference in the proportions between cases and controls in the three age strata used for frequency matching. Specifically, there were fewer control subjects, proportionally, in the 1 to 4 year age group and more in the 10 to 14 year age group $\left(\chi^{2}=\right.$ $9 \cdot 86, \mathrm{df}=2, \mathrm{p}=0.001)$. The mean age for case subjects was 8 years 5 months $(\mathrm{SEM}=0.33$, median $=9$ years) and for controls it was 9 years 3 months ( $S E M=0 \cdot 14$, median $=10$ years).

The relationship between 42 risk factors and childhood pedestrian injury was examined using unconditional logistic regression. Table 1 lists the descriptive statistics for respondents 
Table 1 Distribution of risk factors in children aged 4 to 14 years

\begin{tabular}{lcc}
\hline Factors & Cases (\%) & Controls (\%) \\
\hline Socioeconomic status & $12(12)$ & $55(15)$ \\
$\leq 47$ (high) & $77(79$ & $283(79)$ \\
$48-50$ (middle) & $8(9)$ & $22(6)$ \\
$51+$ (low) & $49 \cdot 3$ & $49 \cdot 1$ \\
Mean & $(0 \cdot 15)$ & $(0 \cdot 08)$ \\
(SEM) & 97 & 360 \\
No & & \\
Volume of traffic (vehicles per week Mon-Fri) & 41956 & 21698 \\
Mean & $(5381)$ & $(2102)$ \\
(SEM) & 29627 & 9172 \\
Median & 76 & 238 \\
No & & $196(55)$ \\
Visual obstacles & $74(76)$ & $223(56)$ \\
Present & & \\
Footpaths & $44(44)$ & 15 \\
Absent & & $(0 \cdot 45)$ \\
Pediatric symptom checklist (PSC) & 17 & 15 \\
Mean & $(0 \cdot 94)$ & 349 \\
(SEM) & 17 & \\
Median & 95 & \\
No & & \\
\hline
\end{tabular}

Table 2 Model of factors associated with injuries to child pedestrians aged 4 to 14 years

\begin{tabular}{|c|c|c|c|}
\hline Variable & $O R$ & $(95 \% C I)$ & $\begin{array}{l}\text { Likelihood ratio test } \\
\text { ( } p \text { value) }\end{array}$ \\
\hline $\begin{array}{l}\text { Socioeconomic status } \\
\text { High } \\
\text { Middle } \\
\text { Low }\end{array}$ & $\begin{array}{l}1 \cdot 00 \\
0 \cdot 79 \\
1 \cdot 34\end{array}$ & $\begin{array}{l}\overline{(0 \cdot 35,1 \cdot 81)} \\
(0 \cdot 41,4 \cdot 28)\end{array}$ & $1.251(0.535)[2]$ \\
\hline Volume of traffic (per & $\begin{array}{r}\text { of } 10 \\
1.12\end{array}$ & $\begin{array}{l}\text { es per day) } \\
(1.05,1 \cdot 19)\end{array}$ & $10.44 \quad(0.001)$ \\
\hline $\begin{array}{l}\text { Visual obstacles } \\
\text { Absent* } \\
\text { Preşent }\end{array}$ & $\begin{array}{l}1 \cdot 00 \\
2 \cdot 68\end{array}$ & $\overline{(1 \cdot 42,5 \cdot 02)}$ & $\overline{10} \cdot 18 \quad(0.001)$ \\
\hline $\begin{array}{l}\text { Footpaths } \\
\text { Present* } \\
\text { Absent }\end{array}$ & $\begin{array}{l}1 \cdot 00 \\
0 \cdot 48\end{array}$ & $\overline{(0 \cdot 27,0 \cdot 87)}$ & $\overline{-}_{5.93}(0.01)$ \\
\hline $\begin{array}{l}\text { Pediatric symptom che } \\
\text { Deviance }=298.95 \mathrm{~d}\end{array}$ & $\begin{array}{l}\text { er unit } \\
1.03\end{array}$ & $\begin{array}{l}\text { ange } 0-70) \\
(1 \cdot 00,1 \cdot 07)\end{array}$ & $3.91 \quad(0.048)$ \\
\hline
\end{tabular}

* Baseline Level. volume of traffic on the roads crossed between Mondays and Fridays. The presence of a "visual obstacle", defined as something within 2 metres of the roadside that was large enough to obscure three quarters of the child on the verge of the child's street of residence, was associated with an increase in the odds of injury of more than 2.6 times $(\mathrm{OR}=2.68,95 \% \mathrm{CI}=$ $1.42,5.02)$ compared with the absence of a "visual obstacle". Furthermore, by restricting the analysis to cases who were injured in his or her street of residence $(n=25)$, the odds of injury associated with visual obstacles on the verge increase $(\mathrm{OR}=2 \cdot 86,95 \% \mathrm{CI}=1 \cdot 28$, $7 \cdot 22)$.

The presence of footpaths on the child's street of residence was also associated with an increase in the likelihood of pedestrian injury. Put another way, the absence of footpaths on the child's street of residence was associated with a $52 \%(\mathrm{OR}=0.48,95 \% \mathrm{CI}=0.27,0.87)$ reduction in the likelihood of injury. This possibly surprising result will be discussed later.

A high or low PSC score indicated the likely presence or absence respectively of a behavioural problem. A positive coefficient was evident for PSC; thus, the more likely the presence of a behavioural problem, the greater the odds of injury. This seems intuitively reasonable.

Having forced socioeconomic status (SES) (as SES was part of the research question) into the model, a " $U$ " shaped relationship was evident between SES of the respondent's family and the odds of pedestrian injury, although this was not significant at the $5 \%$ level. Respondents from families of low SES had $34 \%$ greater odds of injury compared with families of high SES, while middle SES families, those with a social index score between 48 and 51 , had a reduced odds of injury compared with respondents from both high and low SES families.

A second model which was restricted to the age group 4 to 10 years $(n=289)$ in order to assess the only other variable in the data set which had an age restriction, namely, the figure ground discrimination test (ITPA), was similar to the definitive model for children aged 4 to 14 years. Performance on the ITPA was not independently associated with the likelihood of injury (data not shown).

Table 3 reports the most parsimonious unconditional logistic regression model for respondents aged 4 to 14 years $(n=475)$ when the "offset", reflecting the age-sex specific control sampling fractions (see Appendix), was applied. It is apparent that, other than age and sex, the interpretation of the remaining variables in the model remains the same. Age is a significant predictor of the likelihood of injury and an " $n$ " shaped relationship exists between the age of the child and the odds of pedestrian injury. Boys had non-significantly increased odds of injury compared with girls $(\mathrm{OR}=1.02,95 \%$ $\mathrm{CI}=0.54,1 \cdot 75)$.

A further model (see table 4, which consisted solely of age, sex, and SES and in which the "offset" applied enables one to compare the unadjusted ORs for age, sex and socioeconomic status with the ORs for age, sex and socio- 
Table 3 Model of the effects of age and sex on the risk of pedestrian injury

\begin{tabular}{|c|c|c|c|}
\hline Variable & $O R$ & $(95 \% C I)$ & $\begin{array}{l}\text { Likelihood ratio test } \\
\text { ( } p \text { value }[d f]\end{array}$ \\
\hline $\begin{array}{l}\text { Age group }(y) \\
4 \text { to } 6 \\
7 \text { to } 9 \\
10 \text { to } 12 \\
13 \text { to } 14\end{array}$ & $\begin{array}{l}1 \cdot 00 \\
1 \cdot 76 \\
3 \cdot 48 \\
0 \cdot 83\end{array}$ & $\begin{array}{l}-\overline{(0 \cdot 85,3 \cdot 66)} \\
(1 \cdot 64,7 \cdot 38) \\
(0 \cdot 29,2 \cdot 36)\end{array}$ & $13 \cdot 14 \quad(0.044)[3]$ \\
\hline $\begin{array}{l}\text { Sex } \\
\text { Female* } \\
\text { Male }\end{array}$ & $\begin{array}{l}1 \cdot 00 \\
1.02\end{array}$ & $\overline{(0 \cdot 54,1 \cdot 75)}$ & $0.005(0.941)$ \\
\hline $\begin{array}{l}\text { Socioeconomic status } \\
\text { High } \\
\text { Middle } \\
\text { Low }\end{array}$ & $\begin{array}{l}1 \cdot 00 \\
0 \cdot 80 \\
1 \cdot 34\end{array}$ & $\begin{array}{l}\overline{(0.35}, 1 \cdot 82) \\
(0.42,4 \cdot 29)\end{array}$ & $1 \cdot 240 .(0 \cdot 538)[2]$ \\
\hline Volume of traffic (per & $\begin{array}{l}\text { of } 100 \\
1 \cdot 12\end{array}$ & $\begin{array}{l}\text { sper day) } \\
(1.05,1 \cdot 19)\end{array}$ & $10.51 \quad(0.001)$ \\
\hline $\begin{array}{l}\text { Visual obstacles } \\
\text { Absent* } \\
\text { Present }\end{array}$ & $\begin{array}{l}1 \cdot 00 \\
2 \cdot 68\end{array}$ & $\overline{(1 \cdot 42,5 \cdot 02)}$ & $\overline{10} \cdot 19 \quad(0 \cdot 001)$ \\
\hline $\begin{array}{l}\text { Footpaths } \\
\text { Present* } \\
\text { Absent }\end{array}$ & $\begin{array}{l}1 \cdot 00 \\
0 \cdot 48\end{array}$ & $\overline{(0 \cdot 27}, 0 \cdot 87)$ & $\overline{5}_{5.93}(0.015)$ \\
\hline $\begin{array}{l}\text { Pediatric symptom } \mathrm{ch} \\
\text { Deviance }=298.95\end{array}$ & $\begin{array}{l}\text { er unit } \\
1.03\end{array}$ & $\begin{array}{l}\text { ange } 0-70) \\
(1.00,1.07)\end{array}$ & $3.97 \quad(0.046)$ \\
\hline
\end{tabular}

* Baseline Level.

Table 4 The effects of age, sex and socioeconomic unadjusted for exposure and environmental factors

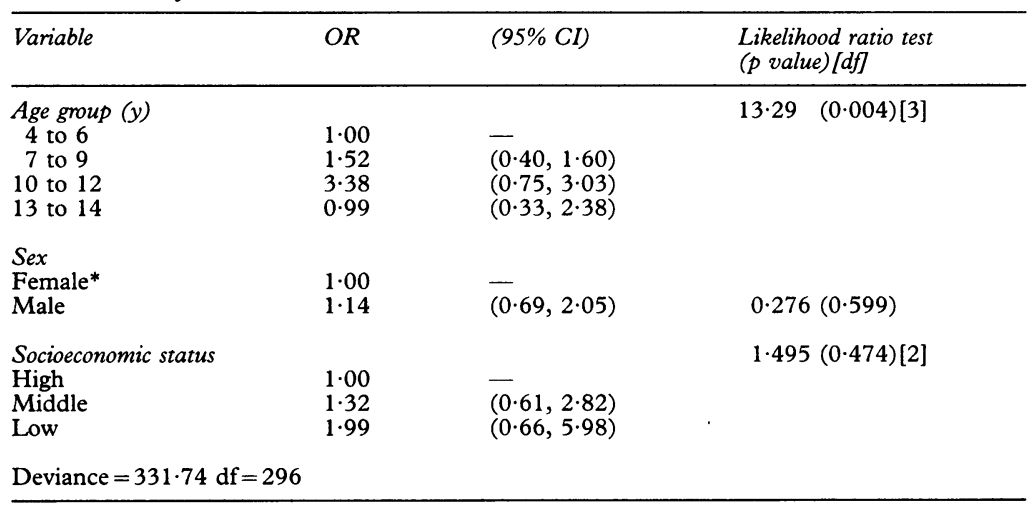

economic status when the child's exposure to the road environment and nature of the road environment to which the child was exposed were taken into account.

Comparison of the ORs in table 4 with the fully adjusted ORs in table 3 indicated that a child's exposure to the road environment, and the nature of that environment partially explains the likelihood of pedestrian injury in the high risk group, namely, children from low socioeconomic areas and males. In other words, the over representation of boys and those from less privileged areas in the injury statistics reflects, at least in part, the environments to which these children are exposed rather than risks directly attributable to maleness or lack of wealth. However, the strong " $n$ " shaped relationship with age group would appear to be independent of the environment to which children are exposed.

\section{Discussion}

A review of the literature highlighted that the available information on childhood pedestrian injuries has been gathered predominantly from descriptive epidemiological studies. A lim- itation of many of these studies has been a lack of comparison between data on injury and data on exposure to the road environment in the same community. Furthermore, many of the studies do not consider all of the contributing factors simultaneously and most do not consider what happened to uninjured children. Consequently, a research approach, such as this study, which compared data on injured and uninjured children and which considered data on exposure and as many as possible of the contributing factors simultaneously was required.

We found that the amount of "habitual" exposure to the road environment and the nature of the road environment to which the pedestrian was exposed influenced the likelihood of injury, particularly in boys and in children aged 13 to 14 years. These effects were most noticeable in children from low socioeconomic areas, but the relationship of socioeconomic environment to childhood pedestrian injury is a complex one. As the over representation of children from low socioeconomic areas and boys in the injury statistics can be explained, in part, by the child's exposure to the road environment, one might suggest that restricting children's exposure to traffic would bring about reductions in child pedestrian injuries. However, researchers ${ }^{34}$ have suggested that restricting a child's exposure to traffic will merely boost the socioeconomic disparity in childhood mortality. For example, Roberts ${ }^{34}$ indicated that poorer families would be least able to escort their children to school by car and supervising children would be more difficult for single parent families. Consequently, one might propose that modifications be made to the environment instead of restricting a child's right to mobility.

Either no or weak to moderate associations between maladaptive behaviours and the risk of childhood pedestrian injury have been reported in the literature. ${ }^{1335-36}$ The inconsistency in the published reports may be due to the types of injuries studied, which varied between studies, as did the tools for assessing the child's behaviour. The findings in the present study, however, indicate that a child's behaviour is significantly associated with the risk of pedestrian injury in children aged 4 to 14 years. Furthermore, a dose-response relationship was evident in that the higher the PSC score, which indicates the likelihood of a behavioural problem, the greater the likelihood of injury.

One should be cautious in looking for a relationship between a child's general behaviour and the risk specifically of pedestrian injury. Notwithstanding this, the questions on the PSC elicit behavioural characteristics such as aggressiveness, lack of attentiveness, a child who acts immaturely or fidgets, and so on. It is likely that characteristics of this nature may compete with the child's ability to focus on potentially hazardous road environments and hence increase that child's potential for injury. Furthermore, it is interesting to note that in the present study the higher PSC scores were more prevalent in boys than girls. 
Although a statistical association is evident between the PSC score and childhood pedestrian injury, it would not be appropriate to focus solely on identifying "at risk" children based on whether they have a behavioural problem or not. To determine whether a child has a behavioural problem is a complex task and one that does not merely require the application of the PSC in the target population. Furthermore, even if "at risk" children could be identified, they would comprise a small group. For example, only $12 \%$ of cases and $7 \%$ of control subjects in this study were identified as having a behavioural problem. Consequently, the potential contribution to prevention from identifying the "at risk" behavioural group, in terms of reducing the incidence of pedestrian injuries, would be marginal.

The volume of traffic on the roads usually crossed was strongly associated with the likelihood of injury. In fact, as the volume of traffic on the roads usually crossed by the child increased, so too did the child's odds of pedestrian injury. Although other studies have not measured the volume of traffic on the $\operatorname{road}(s)$ to which a child is frequently exposed, they do confirm that a high volume of traffic increases the risk of pedestrian injury when the volume of traffic is measured at various injury and control sites. ${ }^{37}$

A number of studies, ${ }^{157}$, have demonstrated the potential for reducing childhood pedestrian injuries through limiting the volume and reducing the speed of vehicular traffic. Using comparable before and after periods, Pharaoh and Russell ${ }^{38}$ reported a reduction of $43 \%$ in the number of pedestrian injuries following the implementation of traffic calming. Not only are there reductions in the number of pedestrian injuries after traffic calming, but also levels of noise and air pollution fall, while pedestrian and cycle activity increase. ${ }^{38}$ Consequently, the establishment of pedestrian friendly environments has the potential for a more general benefit on the public's health.

In contrast to a number of reports, ${ }^{51137}$ this study did not identify on-street parking as contributing to the risk of pedestrian injury. However, until now few studies had determined whether other obstacles to vision, such as semipermanent or permanent objects on the verge of the child's residential street were associated with the likelihood of pedestrian injury. It is evident from this research that semipermanent objects such as rubbish bins and permanent objects such as telephone booths, trees, and post boxes can hide a child while they are walking to the roadside. It is possible that a child's movement from his or her home to the roadside could be completely obscured by obstacles to vision on the verge. Therefore, relocation of semipermanent objects away from the verge, ensuring the design features of permanent structures, minimises the obscuring of children, and regular pruning of street vegetation, should ensure that drivers have a view of the children about to cross the road.

In this study, observations of the road environment were recorded in the street of the child's residence rather than at the site of injury.
Although both sites are equally important, observations undertaken in the child's street of residence have important environmental and educational implications, especially as $25 \%$ of injuries occurred on the child's street of residence. Notwithstanding this, a further study ${ }^{39}$ which conducted observations at the site of injury, reported findings complimentary to those discussed in this study.

The only sub-environment of the road reserve which was significantly associated with the risk of pedestrian injury was the presence or absence of footpaths. The results showed a reduced odds of pedestrian injury associated with the absence of footpaths in the child's street of residence. In fact, children living on residential streets which had no footpaths were $52 \%$ less likely to be injured (OR $=0.48,95 \%$ $\mathrm{CI}=0.27,0.87$ ) than those children with footpaths in the street where they lived. Likewise, a reduced odds of pedestrian injury was also associated with the absence of footpaths at the site of injury $(\mathrm{OR}=0.09,95 \% \mathrm{CI}=0.01$, $0 \cdot 45) .{ }^{39}$

Mueller $e t a l^{\beta 7}$ have reported similar findings, but they only considered footpaths at the site of injury. This finding has not been reported before in relation to the child's street of residence. The explanation proposed by Mueller ${ }^{37}$ that the reduced risk associated with the absence of footpaths was due to footpaths being provided more frequently on busy roads, and that their presence there did not compensate for the increase in risk associated with greater volumes and speed of vehicular traffic is perhaps open to debate. Since they included in their analysis the mean volume of traffic and the posted speed limit at the sites of injury, the reduced risk of injury associated with the absence of footpaths can not be easily explained by greater volumes and speed of vehicular traffic as these have already been taken into account. However, one cannot exclude the possibility that the presence of footpaths may represent residual confounding not controlled for by measuring the volumes and speed of vehicular traffic. We also adjusted for the speed and volume of traffic in our statistical model. It is difficult to determine why the absence of footpaths in the child's street of residence should reduce the likelihood of injury. It could be that where there are no footpaths the child has to walk on the road and he or she is therefore more cautious. Alternatively, the child with a footpath in his or her street may treat the footpath as an extension of the perceived "safe" play area and behave inappropriately in close proximity to traffic, and, therefore, it may be an issue of a child's complacency when in a familiar environment. No matter which the explanation is, they are all amenable, to some degree, to appropriate road safety education.

The aim of this study was not only to determine the major factors related to childhood pedestrian injuries, but also to ascertain to what extent differences in the amount of exposure to the road environment and the nature of the road environment to which a pedestrian is exposed can explain why children of a certain age, sex, and area of residence are at higher 
risk. Although past research has described the pattern of child pedestrian injuries, it has been based on an untested assumption that children of different ages, sexes, and neighbourhoods spend equal amounts of time in equally dangerous road environments. The results from the present study indicate that the over representation in the injury statistics of children from low socioeconomic areas and of boys can be explained, in part, by their pattern of exposure to the road environment - namely, the high volumes of traffic on the roads they cross. Furthermore, the nature of the road environment to which he or she is exposed, such as the absence of footpaths in the streets where they live and kerbside features which obstruct either the child's or driver's view, or both, also affect that child's risk. In short, the results from this study suggest that a reduction in the incidence of childhood pedestrian injuries can best be achieved through modifications to the road environment to which the child is exposed.

The authors wish to thank the Western Australian Health Promotion Foundation (Healthway) for financial support. The position of senior biostatistician at the TVW Telethon Institute of Child Health Research is funded by the NH \& MRC.

1 Guyer B, Talbot AM, Pless IB. Pedestrian injuries to children and youth. Pediatr Clin North Am 1985;32:163-74.

2 Australian Bureau of Statistics. Road traffic accidents reported to the Police Department, Western Australia. Canberra:Australian Bureau of Statistics, 1987. Cat No 9406.5 .

3 Health Department of Western Australia. Hospital morbidity statistics. Perth: Health Department, 1988.

4 Andreassen DC. Preliminary costs for accident-types: acciden costs for project planning and evaluation. Victoria: Australian costs for project planning and evaluation. Victoria: Austr.

5 Andreassen DC. Preliminary costs for accident-types: acciden costs for project planning and evaluation. Victoria: Australian costs for project planning and evaluation. Victoria: Australi

6 Australian Bureau of Statistics. Road traffic accidents involvin casualties admitted to hospital, Australia. Canberra; 1987 Cat No: 9405.0 .

7 Office of Population Censuses and Surveys. Mortality stat istics: cause. London: HMSO, 1986. Series: DH2 No 13.

8 Waller AE, Baker SP, Szocka A. Childhood injury deaths national analysis and geographic variations. Am f Public Health 1989;79:310-15

9 Jonah BA, Engel GR. Measuring the relative risk of pedestrian accidents. Accid Anal Prev 1983;15:193-206.

10 Knighting FA, Colborne HV, Grayson GB. A pilot study of child pedestrians in a residential area. Crowthorne, Berkshire: child pedestrians in a residential area. Crowthorne, Berks

11 Routledge DA, Repetto-Wright R, Howarth CI. The exposure of young children to accident risk as pedestrians. Ergonomics 1974;17:457-80

12 Tight MR. A study of the accident involvement and exposure to risk of child pedestrians on journeys to and from schoo in urban areas. In: Rothengatter T, de Bruin R, eds. Road user behaviour: theory and research. Assen/Maastricht: Van Gorcum, 1988:185-91

13 Pless IB, Verreault R, Tenina S. A case-control study of pedestrian and bicyclist injuries in childhood. Am f Public Health 1989;79:995-98.

14 Backett EM, Johnston AM. Social patterns of road accidents to children. $B M F$ F $1959 ; \mathbf{i}: 409-13$.

15 Joly MF, Foggin PM, Pless IB. A case-control study of traffic accidents among child pedestrians. Proceedings of the International Conference on Traffic Safety. 1991; New the Intern
Delhi.

16 Rowntree G. Accidents among children under two years of age in Great Britain. Fournal of Hygiene 1950;48:323-37.

17 Rivara FP. Child pedestrian injuries in the United States: current status of the problem, potential interventions an future research needs. Am ₹ Dis Child 1990;144:692-96.

18 Roberts I, Streat $S$, Judson J, Norton R. Critical injuries in paediatric pedestrians. NZ Med f 1991;104:247-48.

19 Baker SP, O'Neill B, Ginsburg MJ, Li G. The injury fact book. New York: Oxford University Press, 1992

20 King WD, Palmisano PA. Racial differences in childhood hospitalized pedestrian injuries. Pediatr Emerg Care 1992, 8:221-24

21 Rivara FP, Barber M. Demographic analysis of childhood pedestrian injuries. Pediatrics 1985;76:375-91.

22 Dougherty G, Pless IB, Wilkins R. Social class and the occurrence of traffic injuries and deaths in urban children. Can $\mathcal{F}$ Public Health 1990;81:204-09.

23 Preston B. Statistical analysis of child pedestrian accidents in Manchester and Salford. Accid Anal Prev 1972;4:323-32.
24 Manheimer DI, Mellinger GD. Personality characteristics of the child accident repeater. Child Devel 1967;38:491-513.

25 Read JH, Bradley EJ, Morison JD, Lewall D, Clarke DA. The epidemiology and prevention of traffic accidents involving child pedestrians. Can Med Assoc F 1963;89:687701 .

26 Osborn AF, Morris TC. The rationale for a composite index of social class and its evaluation. British fournal of Sociology 1979;30:39-60.

27 Jellinek MS, Murphy JM. The recognition of psychosocial disorders in pediatric office practice: the current status of the pediatric symptom checklist. $\mathcal{F}$ Dev Behav Pediatr 1990 11:273-78.

28 Kirk SA, McCarthy JJ, Kirk WD. Illinois test of psycholinguistic abilities: examiner manual. Chicago: University of Illinois, 1968.

29 Association for the Advancement of Automotive Medicine. The abbreviated injury scale. Des Plaines, Illinois. 1990.

30 Statistical Analysis System. SAS computer program. Cary, North Carolina: SAS Institute Inc, 1990.

31 Breslow NE, Day NE. Statistical methods in cancer research Volume 1 - The analysis of case-control studies. 1st ed. Lyon: International Agency for Research on Cancer, 1980.

32 Epidemiological Graphics, Estimation and Testing. EGRET computer program. Seattle, Washington: Statistics and Epidemiology Research Corporation, 1993.

33 National Health and Medical Research Council. National health medical research council statement on human experimentation and supplementary notes. Canberra: NHMRC, 1992.

34 Roberts I. Why have child pedestrian death rates fallen? BMF 1993;306:1737-39.

35 Langley JD, Silva PA, Williams SM. Psychosocial factors in unintentional childhood injuries: results from a longitudinal study. Fournal of Safety Research 1987;18:73-89.

36 Smeed RJ. Some aspects of pedestrian safety. Fournal of Transport Economics and Policy 1968;2:255-79.

37 Mueller BA, Rivara FP, Shy-Mine L, Weiss NS. Environmental factors and the risk for childhood pedestrianmotor vehicles collision occurrence. Am 7 Epidemiol 1990; 132:550-60.

38 Pharoah T, Russell J. Traffic calming: policy evaluation in three European countries. London: Department of Planning, Housing and Development, South Bank Polytechnic 1989. Report No: $2 / 89$.

39 Stevenson M, Jamrozik K, Spittle J. A case-control study of traffic risk factors and child pedestrian injury. Int $\mathcal{F}$ Epidemiol 1995;24:957-64.

40 McCullagh P, Nelder JA. Generalized linear models. Monographs on statistics and applied probability 37.2 nd ed. Oxford Chapman and Hall, 1989:206.

\section{Appendix}

Consider a case-control study generated from a base population consisting of $M_{j}$ cases and $N_{j}$ non-cases at level $j$ of a nominal explanatory factor ( $z$ ) with $k$ levels. Designate the levels $1 \ldots \mathrm{k}$ and define level 1 as the baseline category.

The true odds (in the base population) of being a case among individuals at level $j$ of $z$ is $M_{j} / N_{j}$. If the sampling fraction of cases is one (all cases are ascertained) and the sampling fraction of controls at level $j$ is $f_{j}$, the casecontrol study will include $M_{j}$ cases and $f_{j} N$ controls at level $\mathrm{j}$ and the estimated odds at this level will be $M_{j} /\left(f_{j} N_{j}\right)$.

The estimated odds ratio $\left(\Psi_{j}\right)$ for level $j$ compared to level 1 (the baseline category) will be $\left(M_{j} / f_{j} N_{j}\right) /\left(M_{1} / f_{1} N_{1}\right)$. In a standard unmatched case control study $f_{1}=f_{2}=\ldots f_{j} \ldots=f_{k}$ and the estimated odds ratio for level $j$ compared to level 1 will therefore be equivalent to $\left(\mathrm{M}_{\mathrm{j}}\right)$ $\left.N_{j}\right) /\left(M_{1} / N_{1}\right)$, a consistent estimator of the true odds ratio between these two levels in the base population. This is because the common sampling fraction cancels out. However, frequency matching on $\mathrm{z}$ makes it likely that the control sampling fractions will vary between the different levels of $\mathrm{z}$ and will not therefore cancel. In consequence, $\Psi_{j}$ does not then provide a consistent estimate of the true odds ratio in which we are interested. This is the principal reason why one would not generally choose to match on an explanatory variable in which one was primarily interested. 
In a standard logistic regression model, the analysis is carried out on the scale of $\log _{e}$ (odds) and if $\hat{\beta}_{j}$ estimates the $\log _{\mathrm{e}}$ (odds ratio) for level $\mathrm{j}$ compared to level 1 of $\mathrm{z}$ :

$$
\hat{\beta}_{j}=\log _{e}\left(\frac{M_{j} / f_{j} N_{j}}{M_{1} / f_{1} N_{1}}\right)=\log _{e}\left(\frac{\dot{M_{j}} / N_{j}}{M_{1} / N_{1}}\right)-\log _{e}\left(\frac{f_{j}}{f_{1}}\right)
$$

The second term on the right hand side of the equation is the $\log _{e}$ of the ratio of the sampling fractions at levels $j$ and 1 of $z$. Having partitioned off the influence of the varying control sampling fractions in this manner, the first term now provides a consistent estimate of the true $\log _{e}$ (odds ratio) we wish to estimate. This estimate remains consistent if the sampling fraction of cases is less than one. However, if the case sampling fraction also varies with $\mathrm{z}$, full adjustment requires additional components to be introduced into the second term to reflect this variation.

Let us now turn to the present study.

- Knowing the age-sex structure of the base population (which we did) and knowing the age-sex structure of the controls in our study, the age-sex specific control sampling fractions $\left(f_{j}\right)$ could be estimated directly. A vector OFFSET could therefore be generated such that OFFSET $_{\mathrm{g}}$ (the $\mathrm{g}^{\text {th }}$ element of OFFSET) took the value $-\log _{e}\left(f_{h} / f_{1}\right)$ when the $g^{\text {th }}$ individual in the study was at level $\mathrm{h}$ of $\mathrm{z}$.

In order to adjust for the variation of control sampling fractions with age and sex the vector OFFSET was entered into the logistic regression equation as an offset. ${ }^{40}$ An offset may be viewed as an explanatory variable with a regression coefficient which is forced to be one. This takes up the impact of the variation in sampling fraction introduced by the frequency matching (the second term on the right hand side of the equation above) and leaves $\hat{\beta}_{j}$ to estimate the first term which provides a consistent estimate of the true odds ratio of interest in the base population. In this particular study, there was no evidence that the response of cases varied markedly with either age or sex and there was therefore no need to modify the elements of OFFSET to reflect case sampling fractions. 